$\frac{12}{7-95958501}$

UCRL-ID-118538

\title{
Hydronuclear Experiments: Why They Are Not a Proliferation Danger
}

K. C. Bailey

September 28, 1994

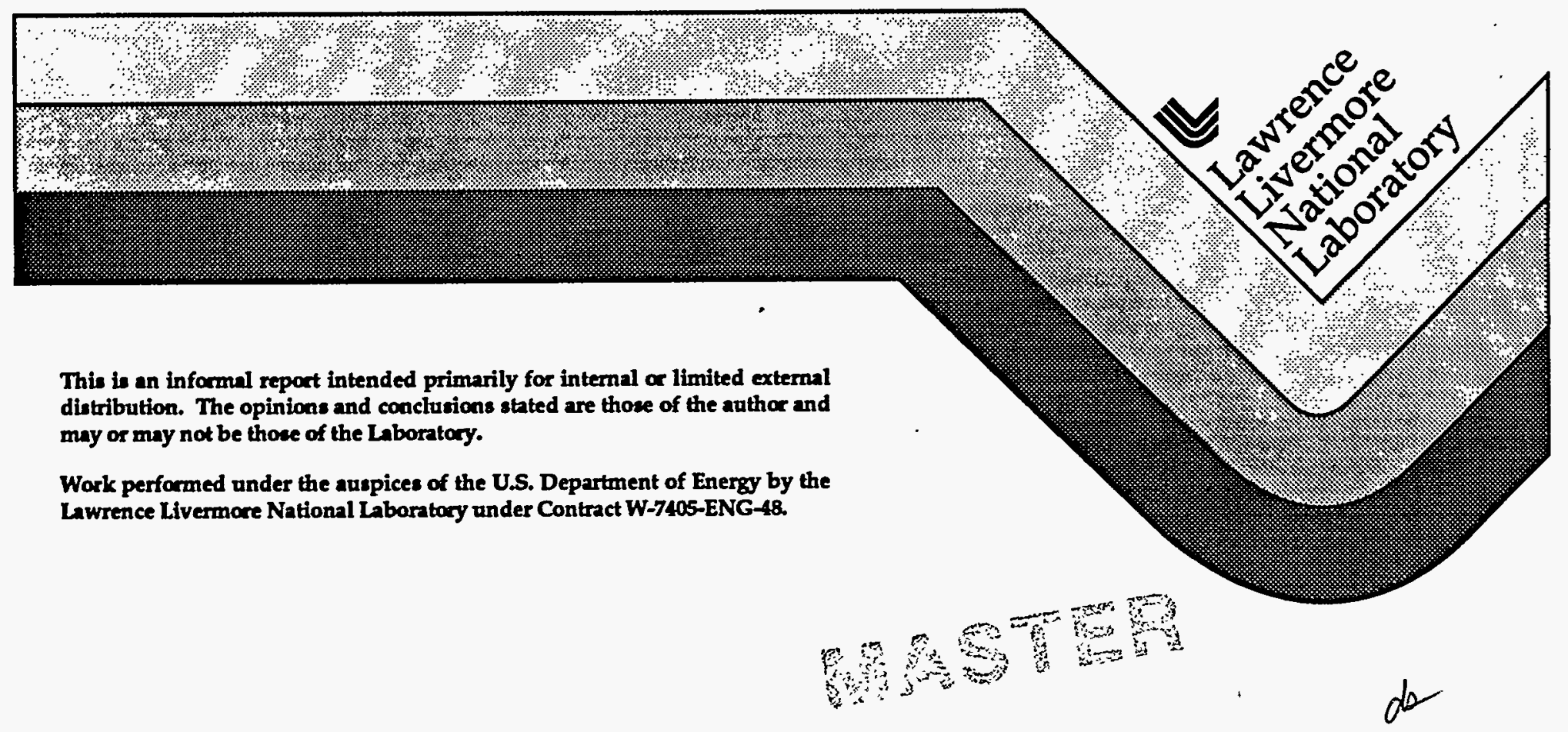




\section{DISCLAIMER}

This document was prepared as an account of work sponsored by an agency of the United States Government. Neither the United States Government nor the University of California nor any of their employees, makes any warranty, express or implied, or assumes any legal liability or responsibility for the accuracy, completeness, or usefulness of any information, apparatus, product, or process disclosed, or represents that its use would not infringe privately owned rights. Reference herein to any specific commercial product, process, or service by trade name, trademark, manufacturer, or otherwise, does not necessarily constitute or imply its endorsement, recommendation, or favoring by the United States Government or the University of California. The views and opinions of authors expressed herein do not necessarily state or reflect those of the United States Government or the University of California, and shall not be used for advertising or product endorsement purposes.

This report has been reproduced directly from the best available copy.

Available to DOE and DOE contractors from the

Office of Scientific and Technical Information

P.O. Box 62, Oak Ridge, TN 37831

Prices available from (615) 576-8401, FTS 626-8401

Available to the public from the

National Technical Information Service

U.S. Department of Commerce

5285 Port Royal Rd.,

Springfield, VA 22161 


\section{DISCLAIMER}

Portions of this document may be illegible in electronic image products. Images are produced from the best available original document. 


\section{Hydronuclear Experiments: Why They Are Not A Proliferation Danger*}

When faced with the political imperative of an end to nuclear testing, the nuclear design community responsible for the safety and reliability of the US nuelear stockpile made two essential points: a) that no other technologies could fully replace the data and confidence that result from nuclear testing, but b) a combination of technologies could provide adequate assurance of safety and reliability. One of those technologies identified was hydronuclear experiments (HNEs). These are highly sophisticated experiments utilizing devices whose nuclear yield is less than that of the high explosive, and whose results must be interpreted by using extensive data on actual, full-scale nuclear explosives testing.

Now that the negotiations for a Comprehensive Test Ban Treaty (CTBT) are underway, some critics are arguing that HNEs should be prohibited under the CTBT. A principal reason cited is that HNEs are useful for developing new designs of nuclear weapons 1 - either by advanced nuclear weapon states or proliferants-but are of only marginal utility in assessing the safety of existing designs. Neither argument is accurate.

\section{HNEs Are of Very Limited Use in Designing New Devices}

HNEs are unnecessary to develop a nuclear weapon of 5-30 kt. If a country wants to design and build a simple fission or gun-assembly weapon, there is no need for any nuclear testing to have high confidence of achieving significant yield. South Africa, for example, developed and built nuclear weapons in which it had high confidence without nuclear testing.

If a country pursues boosted fission weapons or thermonuclear secondaries, HNEs will be an ineffective tool. Also, HNEs cannot be used to optimize the

\footnotetext{
1Thomas B. Cochran and Christopher E. Paine assert in their paper "Hydronuclear Testing and the Comprehensive Test Ban: Memorandum to Participants, JASON 1994 Summer Study" (July 1 1994) that hydronuclear experiments provide a significant and unique capability to develop simple implosion weapons of 5 to $30 \mathrm{kt}$, sophisticated weapons of yield up to a megaton, and advanced micronuclear weapon with yields of 5 to 500 tons.
} 
advanced designs used by existing nuclear weapons states; they are far too low in energy to confirm that boosting will occur in boosted designs, much less provide useful information for staged thermonuclear weapons. They cannot accurately project the neutron multiplication rate at the time a device explodes. The additional information obtained from HNEs does not significantly improve the reliability of yield estimates for new small unboosted devices beyond that which can be obtained from non-nuclear experiments.

\section{Most design information is available from other means.}

Could an advanced proliferant state use HNEs to develop advanced designs? Indeed, HNEs can give some information that would be useful to a proliferant, but most of the information can be acquired more easily and at less expense by other means such as nonnuclear experiments and computer calculations of nuclear explosions. Examples include:

- $\quad$ HNEs can give information on the neutronics and average compression of new nuclear weapons. However, such information can also be obtained from hydrodynamic experiments and testing of neutronics codes against pulsed nuclear reactors and laboratory-scale critical assemblies.

- $\quad$ HNEs can be used to improve Equation of State (EOS) estimates for fissile material. An EOS of uranium also can be constructed from a combination of theory and experimental data, an approach the Iraqis were taking. A proliferant could understand EOS for special nuclear materials more easily and at less cost by conducting laboratory experiments than by HNEs.

\section{HNEs do not predict device yield.}

To predict the yield of a device, the actual fission neutron multiplication rate at the time of explosion must be known. HNE data cannot be directly extrapolated to give the rate at full yield principally because the neutron multiplication rate measured in an HNE is different from that in an actual 
weapon. The most sensitive parameters for yield prediction involve energy distribution during the explosion phase of a fission weapon, and this phase does not occur in an HNE. For this reason, sophisticated computational models, calibrated to high-yield nuclear tests, are required to interpret the hydronuclear data. Even US designers are not willing to use hydronuclear data to develop new, advanced-technology devices.

Another incorrect criticism of HNEs is that such experiments can confirm operation of a nuclear explosive until just prior to boosting. An HNE cannot measure the thermodynamic conditions just prior to boosting because the actual pre-boost conditions do not occur in such an experiment. The implosion diagnosed in a hydronuclear experiment is not the same implosion as occurs in the actual weapon, so it is inaccurate to claim that HNEs give pre-boost data.

\section{If one can conduct a nuclear test, HNEs are unnecessary.}

Some critics of HNEs claim that these experiments, when coupled with a small clandestine nuclear test, can confirm new boosted device technology. In fact, if a nuclear test is conducted, there is no need for HNEs. A kiloton test, ${ }^{2}$ unlike an HNE, provides data on the neurton multiplication rate, as well as on compression and geometry of a fully imploded device.

\section{HNEs Are Useful for Assessing Warhead Safety}

A principal use of $\mathrm{HNEs}$ would be to experimentally assess the one-point safety of a nuclear device, an extremely important function. ${ }^{3}$ HNEs are in fact the only experimental method available to assess the safety of a stockpile weapon, with its stockpile components. Modern primaries are carefully designed to be one-point safe, but some components (such as the chemical high explosive) are unstable. We do not know what the properties of these materials will be when they have aged for years in proximity to other unstable components.

2 This is acutally the more worrisome scenario, given that there are no current technical means for detecting a clandestine $1 \mathrm{kt}$ nuclear test.

${ }^{3}$ During the 1958-61 nuclear testing moratorium, the United States conducted HNEs primarily to determine if some nuclear systems were one-point safe. 
It is also possible that HNEs can help establish reliability of the stockpile. Clearly, inspections and hydrodynamic testing, followed by numerical simulations, are insufficient techniques for determining the reliability of devices in the stockpile. Recent nuclear testing history shows that the computational codes still contain many approximations that can lead to error. There are cases in which the results of hydrodynamic experiments on a given device appeared acceptable to designers, but subsequent nuclear testing of the device produced substantially different yields than predicted. Furthermore, there are instances in which warhead defects were not detected by hydrodynamic or other surveillance measures.

In addition to assessing safety and, possibly, reliability, HNEs can be used to demonstrate the effectiveness of devices to disable nuclear weapons. Thus, HNEs are likely to be essential to developing capabilities to deal with terroristdelivered nuclear weapons.

\section{HNEs and Verification}

If $\mathrm{HNEs}$ are declared and verification is allowed, it will be possible to measure the yield of the experiment to determine compliance. If an HNE is conducted secretly, the characteristic extremely low level of energy released will make it difficult, if not impossible, to detect. The same problem of verification, however, is true of small-yield nuclear tests. Thus, if a country were to wish to cheat, it would probably do so by conducting a nuclear test rather than a hydronuclear experiment. 